\title{
LA-UR-20-27790
}

Approved for public release; distribution is unlimited.

Title:

Author(s):

Intended for:

Issued:
A Whirlwind History of Cryptography

Pearce, Lauren

Local LANL Presentation

2020-10-01 
Disclaimer:

Los Alamos National Laboratory, an affirmative action/equal opportunity employer, is operated by Triad National Security, LLC for the National Nuclear Security Administration of U.S. Department of Energy under contract 89233218CNA000001. By approving this article, the publisher recognizes that the U.S. Government retains nonexclusive, royalty-free license to publish or reproduce the published form of this contribution, or to allow others to do so, for U.S. Government purposes. Los Alamos National Laboratory requests that the publisher identify this article as work performed under the auspices of the U.S. Department of Energy. Los Alamos National Laboratory strongly supports academic freedom and a researcher's right to publish; as an institution, however, the Laboratory does not endorse the viewpoint of a publication or guarantee its technical correctness. 


\section{A Whirlwind History of Cryptography}

Lauren Pearce

- Los Alamos NATIONAL LABORATORY 


\section{The Big Picture}

- Cryptography and cryptanalysis developed side by side in arms race.

- Algorithm development stagnated pending cracking. Once a method of crypto was cracked, development took off.

- Cryptography and cryptanalysis drove developments in math, linguistics, information theory, and quantum theory. Pushed development of the first computers. 


\section{Spartan Scytale}

- First military crypto device, used extensively during the Peloponnesian wars

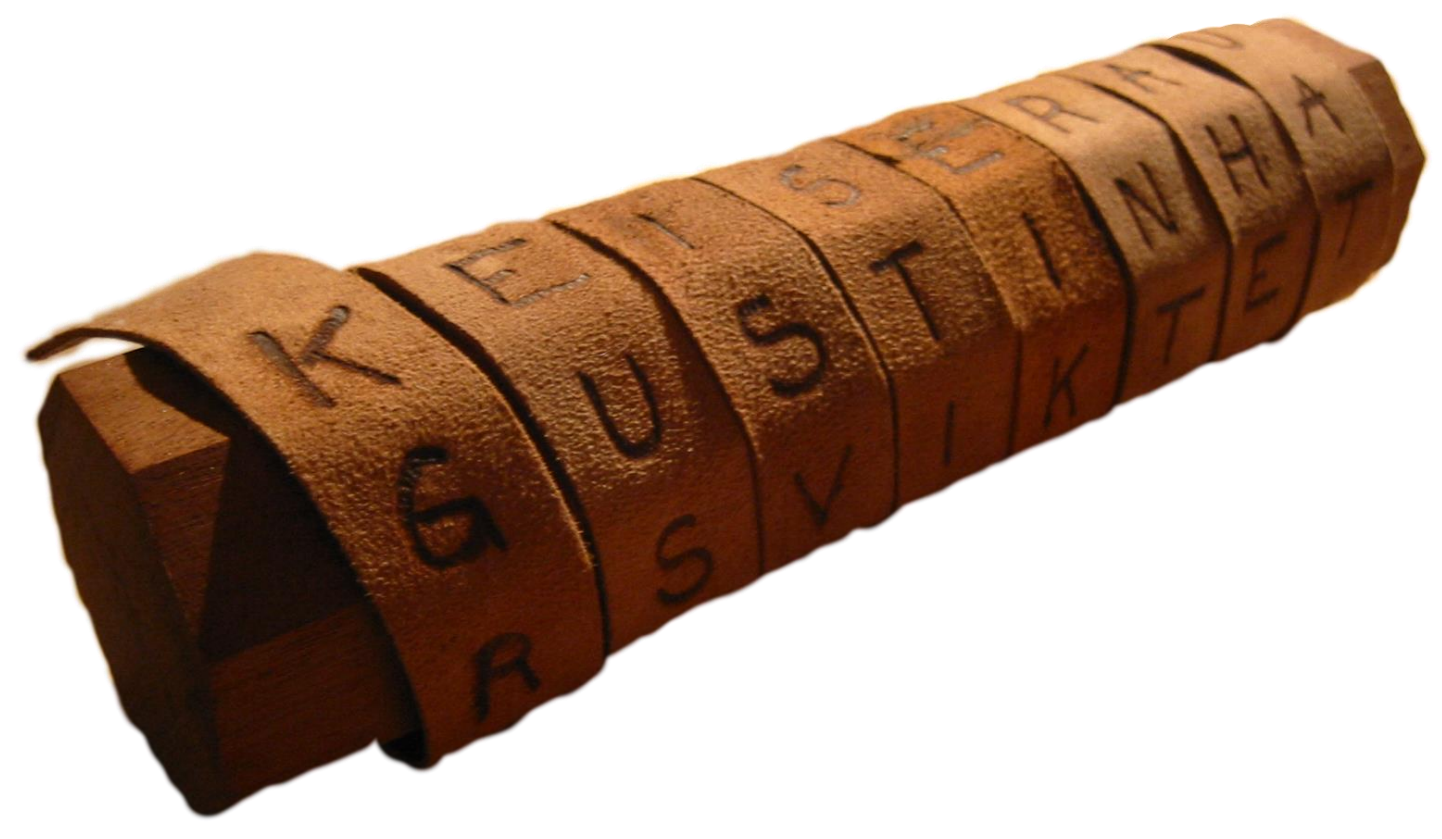




\section{Caesars' Use of Ciphers}

- First documented military use of substitution cipher - Caesar sent a message to Cicero in the Gallic Wars in which each Roman letter was substituted with a Greek letter.

- The "Caesar Cipher" was documented by Suetonius's "Lives of the Caesars LVI" - shifted each letter 3 places. 


\section{Cryptanalysis in the Abbasid Caliphate (750-1258)}

- Theologians studied the etymology of words and structure of sentences to determine what texts were consistent with the linguistic patterns of Mohammed.

- This naturally led into frequency analysis.

- First succeeded in breaking monoalphabetic substitution cipher - a cipher that had been in use unbroken for hundreds of years. 


\section{Cryptanalysis in The Renaissance}

- First documentation of breaking of monoalphabetic substitution ciphers in the west occurred during the Renaissance - unknown if independently discovered or imported from the Arab world.

- Francois Viete - A French cryptanalyst who was so good that King Phillip II of Spain petitioned the Vatican that the only explanation for his cryptanalysis was that he was an "archfiend in league with the devil", arguing that he should be tried for his demonic deeds

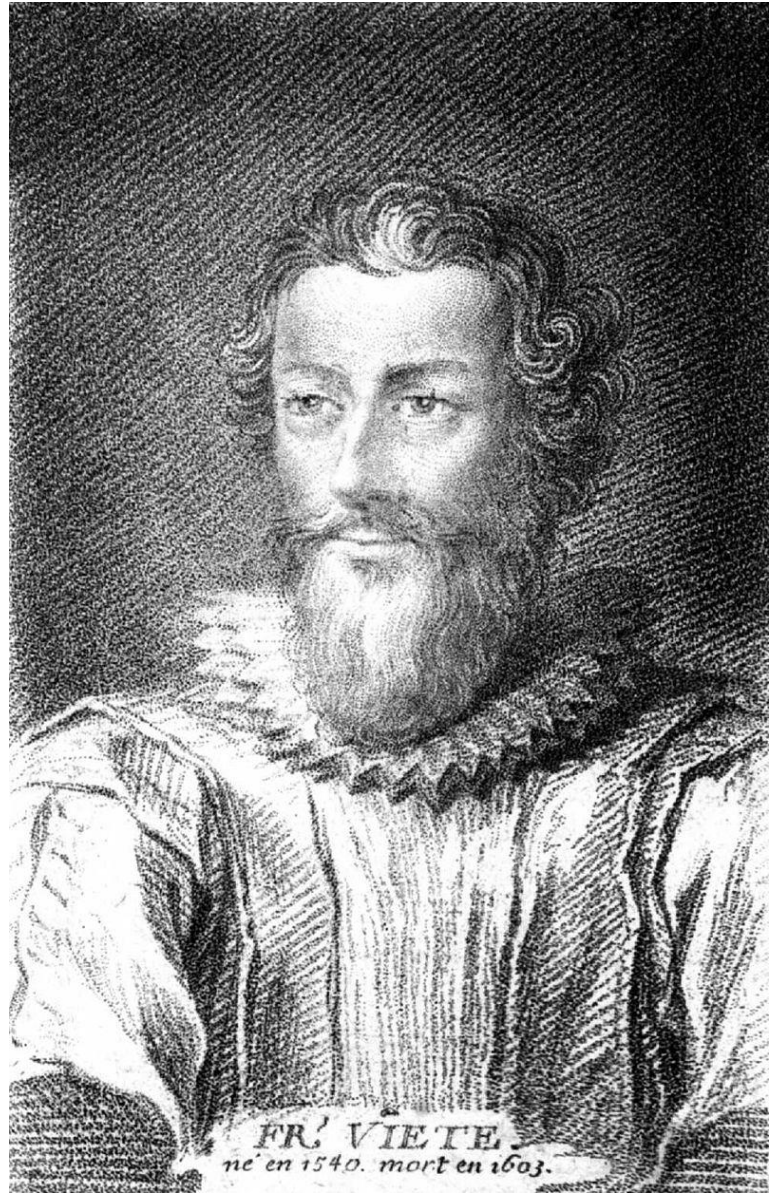




\section{Advances in Crypto - Nomenclators and Nulls}

- Introduced nulls and deliberate misspellings that would mess with the frequency of letters. Also added code words.

- Nomenclator - A system that relies on a cipher alphabet to encrypt, but some of the underlying plaintext is further encrypted with codewords.

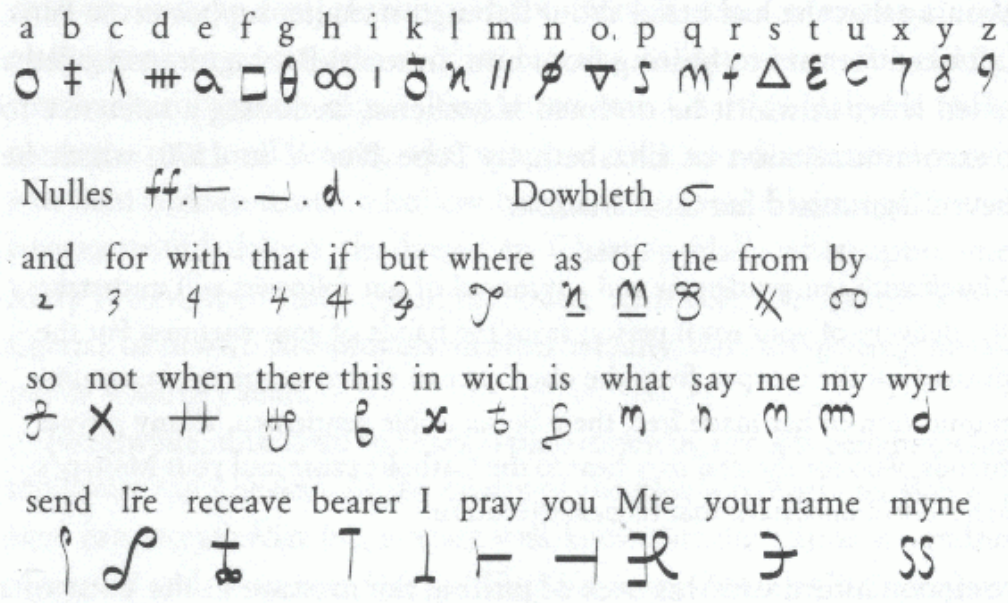




\section{Vigenere (1586)}

- A single message is encrypted with multiple different substitution alphabets.

- Breaks straight frequency analysis because any plaintext character can be represented by <keylength> different characters.

- Has an enormous number of keys - Can't be brute forced by humans.

- Published "A Treatise on Secret Writing" in 1586, but was largely ignored for 200 more years.

Keyword

Plaintext

Ciphertext
WH I T E WH I T E WH I TEWH I T E W H I d i vert t roops o e a s t r i g e Z P D X V P A Z H L L B H I W Z B KM Z N M 


\section{Homophonic Substitution Cipher}

- Each letter is replaced with a variety of substitutes, the number being proportional to the frequency of letters.

- Can create a cipher in which each letter occurs with equal frequency.

- Still susceptible to frequency analysis using n-grams, but much more difficult.

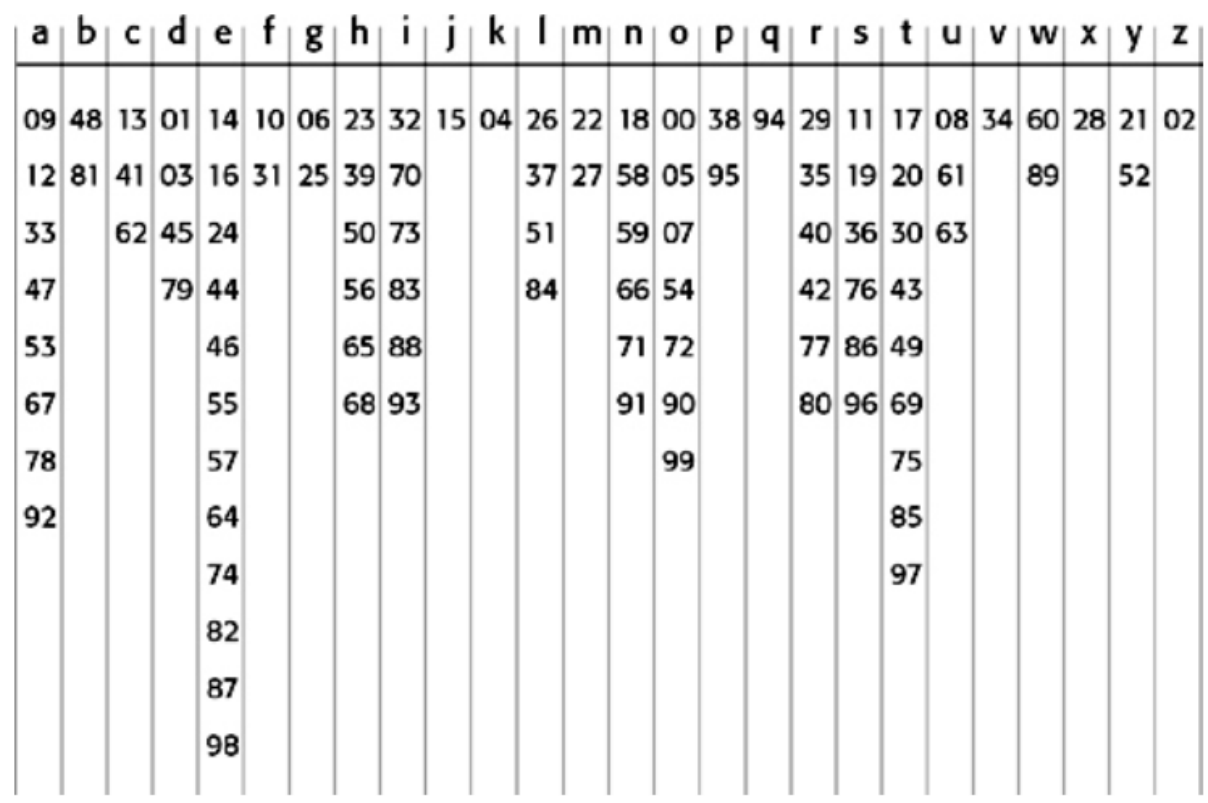




\section{The Great Cipher (1643)}

- Developed by Father-Son team of Rossignols, cryptanalysts to Louis XIV

- Was never broken, and then we lost the codebook - many papers of the French archives could not be read

- Deciphered in 1890 by Etienne Bazeries

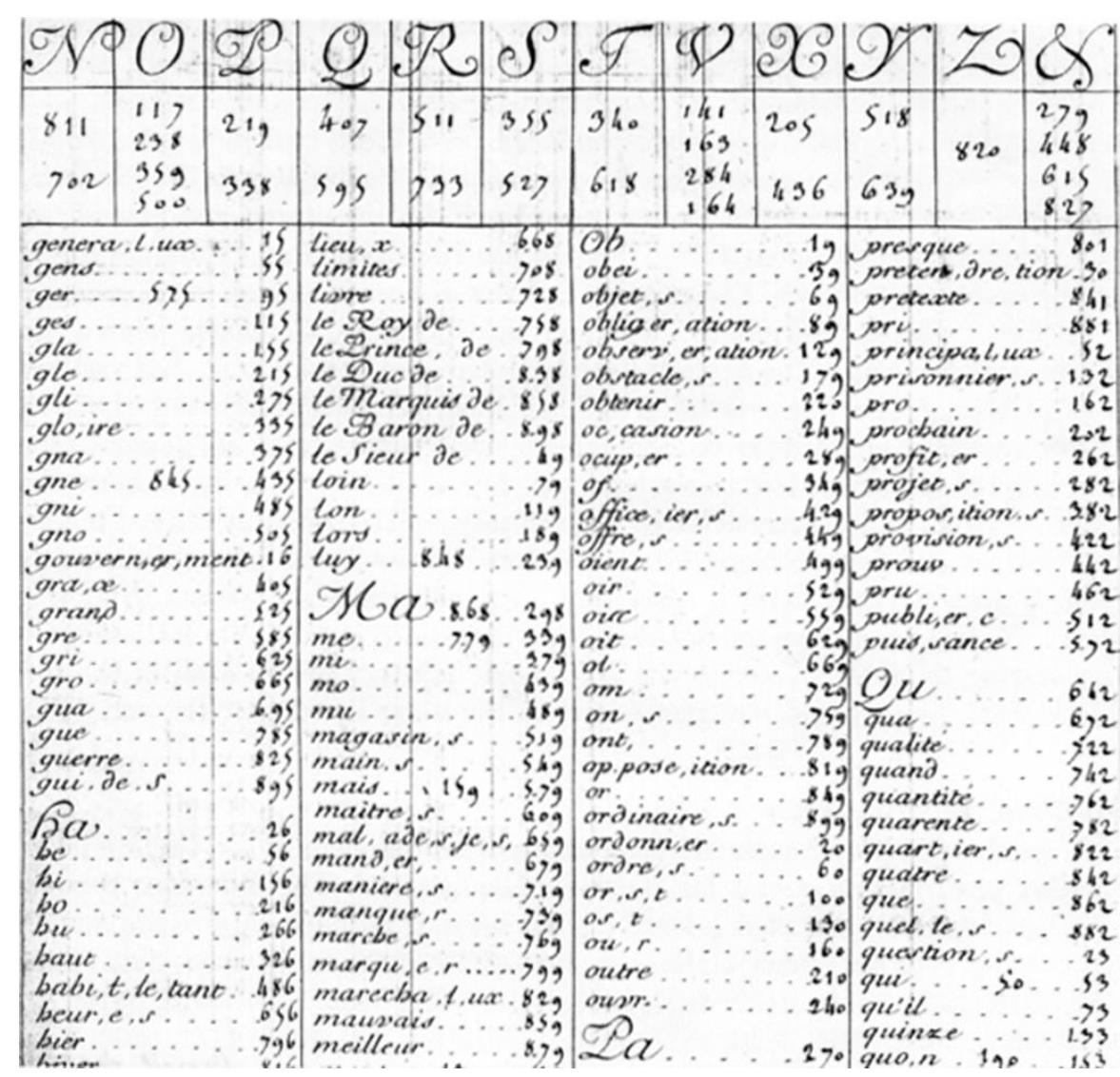




\section{Black Chambers (1700s)}

- Melt off the seals, copy the letter, reseal with a counterfeit seal, send it on its way.

- Viennese Black chamber so good at this that it sold information to other powers

- Effectively made all forms of crypto in use insecure - pushed a shift to polyalphabetic ciphers such a Vigenere. 


\section{Development of the Telegraph (1839)}

- Messages had to go through the hands of the telegraph operators, destroying confidentiality.

- Cipher of choice at this point was Vigenere, known as "Le Chiffre Indechiffrable" - the indecipherable cipher.

- For the first time, there was public interest in Crypto 


\section{Charles Babbage (1854)}

- Best known for developing the first blueprints for something resembling a modern computer

- Broke Vigenere, likely in 1854, but he never published it. This knowledge was discovered based on analysis of his notes in the $20^{\text {th }}$ century.

- Previously, breaking vigenere was attributed to Friedrich Wilhelm Kasiski in his 1863 publication of "Secret Writing and the Art of Deciphering". 


\section{Kerchkhoff's Principle (1883)}

-1883, stated by Dutch linguist August Kerchkhoffs Von Nieuwenhof in book "La Cryptographie Militaire"

- "The security of the cryptosystem must not depend on keeping secret the crypto-algorithm. The security depends only on keeping secret the key." 


\section{WWI - Cutting Communications Cables}

- Before dawn on the first day of WWI, the British had already cut Germany's transatlantic cables.

- This forced Germany to rely on the communications systems of other countries (typically Sweden or America) - the routes of which touched England.

- This ultimately enabled the decryption of the Zimmerman Telegram, one of the major factors bringing the United States into the war. 


\section{WWI - ADFGVX Cipher}

- The cipher used by the German army on the Western front.

- Broken by Georges Painvin, a French cryptanalyst

- Often revealed troop movements for offensives prior to them being launched.

\begin{tabular}{|c|c|c|c|c|c|c|}
\hline & A & D & F & G & V & X \\
\hline A & N & A & 1 & C & 3 & H \\
\hline D & 8 & T & B & 2 & O & M \\
\hline F & E & 5 & W & R & P & D \\
\hline G & 4 & F & 6 & G & 7 & I \\
\hline V & 9 & J & 0 & K & L & Q \\
\hline X & S & U & V & X & Y & Z \\
\hline
\end{tabular}

\begin{tabular}{|c|c|c|c|c|c|c|c|c|c|c|c|c|c|}
\hline $\mathbf{A}$ & $\mathbf{T}$ & $\mathbf{T}$ & $\mathbf{A}$ & $\mathbf{C}$ & $\mathbf{K}$ & $\mathbf{A}$ & $\mathbf{T}$ & $\mathbf{1}$ & $\mathbf{2}$ & $\mathbf{0}$ & $\mathbf{0}$ & $\mathbf{A}$ & $\mathbf{M}$ \\
\hline $\mathrm{AD}$ & $\mathrm{DD}$ & $\mathrm{DD}$ & $\mathrm{AD}$ & $\mathrm{AG}$ & $\mathrm{VG}$ & $\mathrm{AD}$ & $\mathrm{DD}$ & $\mathrm{AF}$ & $\mathrm{DG}$ & $\mathrm{VF}$ & $\mathrm{VF}$ & $\mathrm{AD}$ & $\mathrm{DX}$ \\
\hline
\end{tabular}




\section{WWI - Advent of Traffic Analysis}

- The French had 6 listening stations which they used to triangulate the location from which traffic emanated.

- Could ascertain quantity of traffic, location and movement of traffic, and even who was sending the traffic without breaking any ciphers.

- Could recognize the "fist" of the major German telegraph operators, like modern fingerprinting through typing patterns. 


\section{WWI - Room 40}

- Cryptanalysis department of the British Admiralty

- Decoded the three primary German naval ciphers and were waiting nearly every time the High Seas Fleet ventured out.

- They had captured codebooks for 2 different codes, and were given a third by the Russians.

- Some Cryptanalysis, but most of their work was from captured codebooks

- It was in Room 40 that the Zimmerman Telegram was decoded 


\section{The One Time Pad (1919)}

- Basically a Vigenere cipher with a key as long as the plaintext. Key can be used only once.

- The only cipher we've found that is provably unbreakable.

- Unbreakable IF:

- Key is truly random

- Key is at least as long as plaintext

- Key is never reused

- Key is kept secret 


\section{The One Time Pad - Weaknesses}

- Why didn't the game end here?

- Requires a random key for every message. Random is really hard, especially in 1919.

- Distribution of those random keys is difficult, especially since interception is a major concern.

- If a book of keys is intercepted, game over.

- Everyone has to stay on the same page, literally. And the page turns every single message. 


\section{The Enigma: Foundations}

- The cipher disk was invented in the 15th century. Early machine ciphers mechanized them to create a quick way to implement a monoalphabetic substitution cipher.

- German Inventor Arthur Scherbius - Set out to replace pencil and paper ciphers with machines. Had a background in electrical engineering.

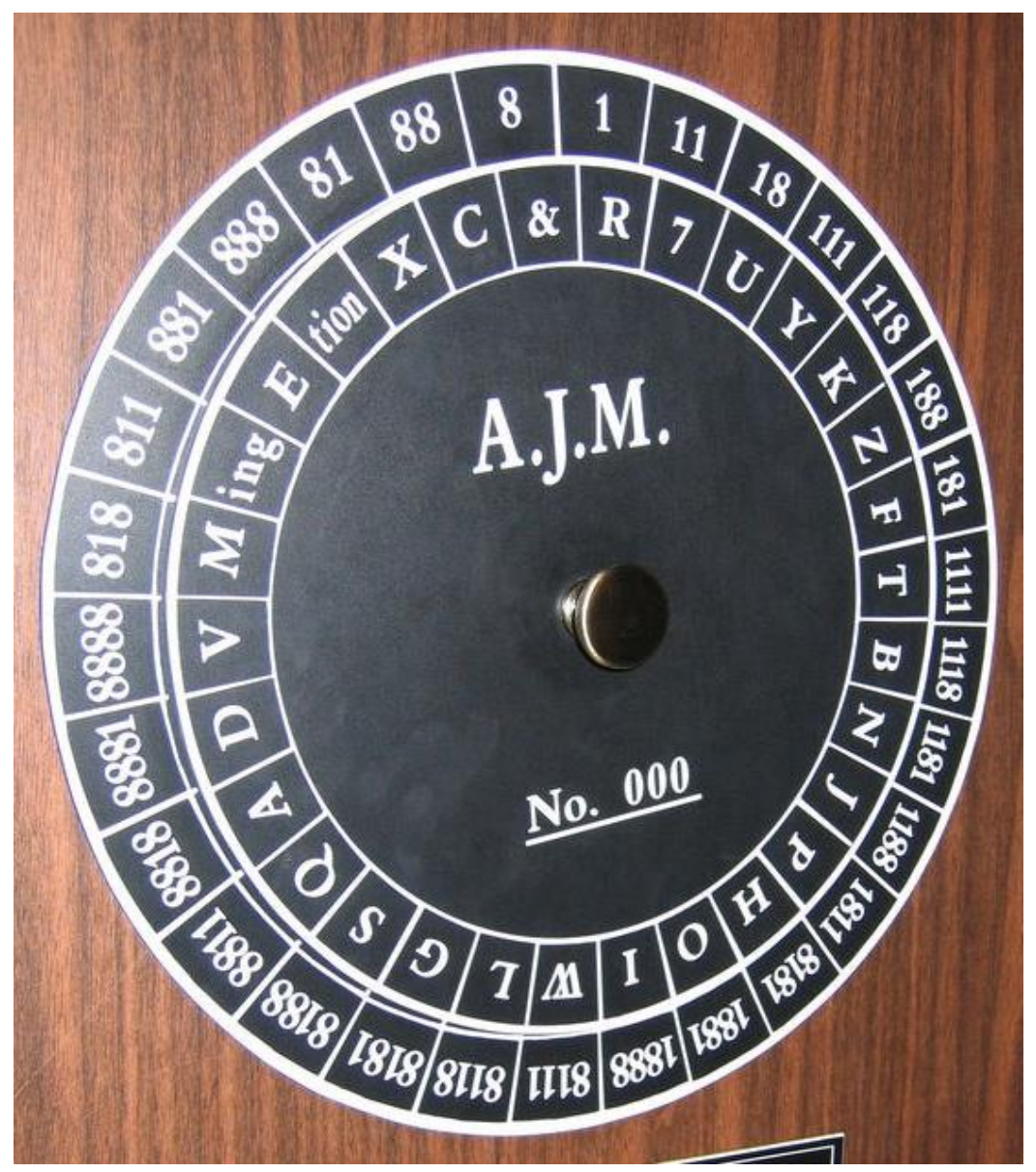




\section{The Enigma: Fundamentals}

- The Enigma can be thought of as a series of mechanized cipher disks that cycle at different rates. In addition, there is plugboard that switches letters before they even go into the cipher disks.

- Enigma had a reflector feature, which made it reversible - type cipher text in, it spits plaintext out.

- Enigma's configuration (order of disks, position of plugs) can be thought of as its key.

- With 3 scramblers, arranged in 6 orderings, and a plugboard swapping 6 pairs of letters, the total number of keys for the INITIAL Enigma was $10,000,000,000,000,000$. 


\section{The Enigma: Adoption}

- 1923 - Churchill published "The World In Crisis", in which he revealed not only that GB had broken Germany's codes in WWI, but exactly how valuable the information gleaned through cryptanalysis had been.

- Later in 1923, the British Royal Navy followed up on this and published their official history, reiterating everything Churchill had just said.

- This convinced Germany that they needed better codes, and they turned to the Enigma in 1926

- The German Military would ultimately buy 30,000 Enigmas

- Note: The wiring of the Enigma's sold to the German military was different from the wiring of the few sold for commercial use. 


\section{Cracking the Enigma: Setting the Stage}

- England began intercepting Enigma enciphered messages in 1926, and were baffled. The Allies gave up on Enigma. They cut back their departments and the number and quality of cryptanalysts dwindled.

- Poland experienced success deciphering enemy messages during the Russo-Polish war in 1919-1920.

- Poland knew what a precarious position they were in and were desperate for intelligence at all

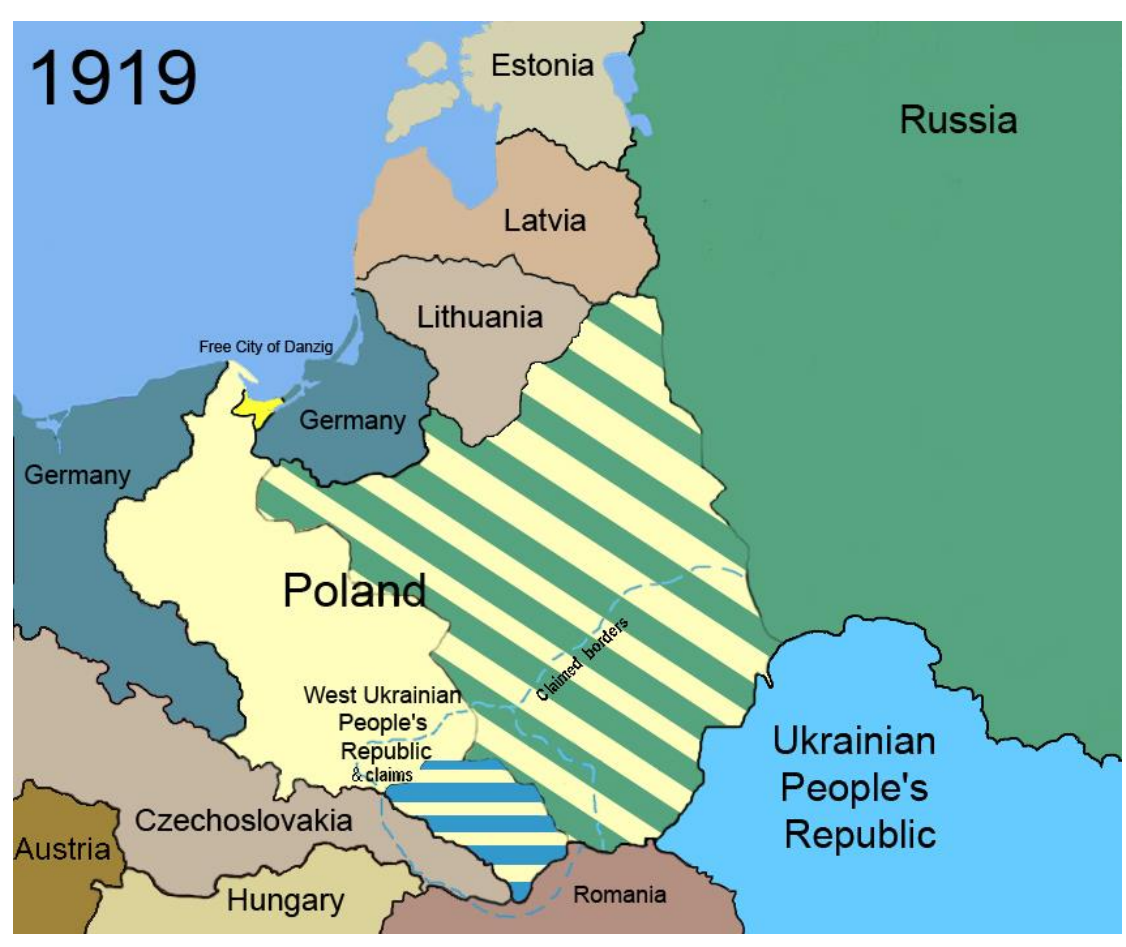
times. 


\section{Cracking Enigma: Humint}

- Hans-Thilo Schmidt provided the French with the German instructions for using the Enigma. These instructions contained enough information for the French to make an accurate replica of the German Enigma.

- The French didn't even bother to build a replica - they were convinced the system was uncrackable.

- The French had signed a military cooperation agreement with the Poles, who had already expressed interest in anything Enigma related. Accordingly, they passed the documents provided by Schmidt to the Poles. 


\section{Cracking Enigma: Day Keys and Message Keys}

- A message key is generated "randomly", and used to encrypt the message to be transmitted. The message key itself is encrypted using the day key, then appended to the beginning of the encrypted message twice.

- To decrypt: Use the day key to decrypt the message key, use the message key to decrypt the message.

- The message key is 3 characters specifying the scrambler disk orientations. Sent twice, this is 6 characters at the beginning of each message. 


\section{Cracking Enigma: Marian Rejewski}

- Brilliantly separated the problem of the rotors from the problem of the plugboard.

\section{BJGTDN LIFBAB ETULZR TFREII}

- With just the 6 letters (3 pairs) at the beginning of each message, Rejewski was able to mathematically define relationships between letters.

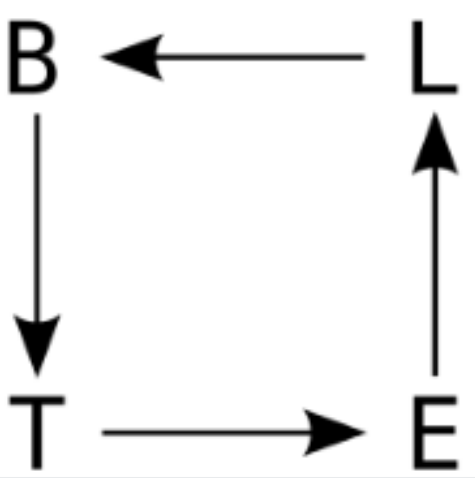




\section{Cracking Enigma: Automating the Process}

- Using his replica enigma, he catalogued the relationships for each of the possible 105,456 scrambler settings.

- Using his catalogue of settings, Rejewski created a machine that could leverage the repeated key to find the day key in roughly two hours.

- He called this machine a "bomba". This is history's first example of mechanized decipherment. 


\section{Cracking Enigma: Germany Hardens Enigma}

- December 1938 - German Cryptographers significantly changed the Enigma.

- Added 2 new scramblers to the deck (though only 3 were used at any given time), increasing the possible number of arrangements to 60 .

- Increased the number of plugboard cables from 6 to 10, meaning there are now 20 swapped letters.

- Net result: Increased the keyspace to $159,000,000,000,000,000,000$

- Rejewski needed 60 machines per bomba to break this version. This was well outside of his budget. Rejewski was stuck. 


\section{Cracking Enigma: Ship it to England}

- 1939 - Signs Hitler plans to invade Poland are increasing, war in Poland is obviously imminent.

- June 30 - Poles invited the British and French to Warsaw to discuss urgent matters concerning Enigma.

- July 24 - British and French Cryptanalysts arrive in Warsaw and are shown Rejewski's bomba. Poles give them Enigma replicas and blueprints for the bomba.

- September 1 - Hitler invaded Poland. 


\section{Cracking the Enigma: The Enigma in England}

- What was Room 40 in WWI outgrew Room 40 and moved to Bletchley Park.

- Previously, linguists had dominated cryptanalysis. Poland had shown the importance of mathematics in breaking Enigma - England began recruiting mathematicians.

- With their significant resources, England was able to build several 60unit bombas and were able to break the Enigma day key within hours each day. 


\section{Cracking the Enigma: The Enigma in England}

- What was Room 40 in WWI outgrew Room 40 and moved to Bletchley Park.

- Previously, linguists had dominated cryptanalysis. Poland had shown the importance of mathematics in breaking Enigma - England began recruiting mathematicians.

- With their significant resources, England was able to build several 60unit bombas and were able to break the Enigma day key within hours each day. 


\section{Cracking the Enigma: Humans Undermining Crypto}

- Cillies:

- Message keys were supposed to be random, but humans are really bad at random.

- Operators would often pick consecutive keys from the Enigma keyboard or use the same message key frequently.

- Cryptanalysts would try the cillies before the bomba, and it often paid off.

- Stereotypes

- Predictable texts enabling known plaintext attacks.

- Decreasing Randomness in an effort to increase it

- No scrambler could remain in the same position for two days in a row.

- Plugboard settings could not swap between any letter and its neighbor 


\section{Cracking the Enigma: Alan Turing}

- England anticipated that the Germans would eventually recognize the weakness they were introducing by repeating the message code, and change their message format.

- Turing was asked to find an alternate way to decrypt Enigma so that England would not lose visibility should this happen.

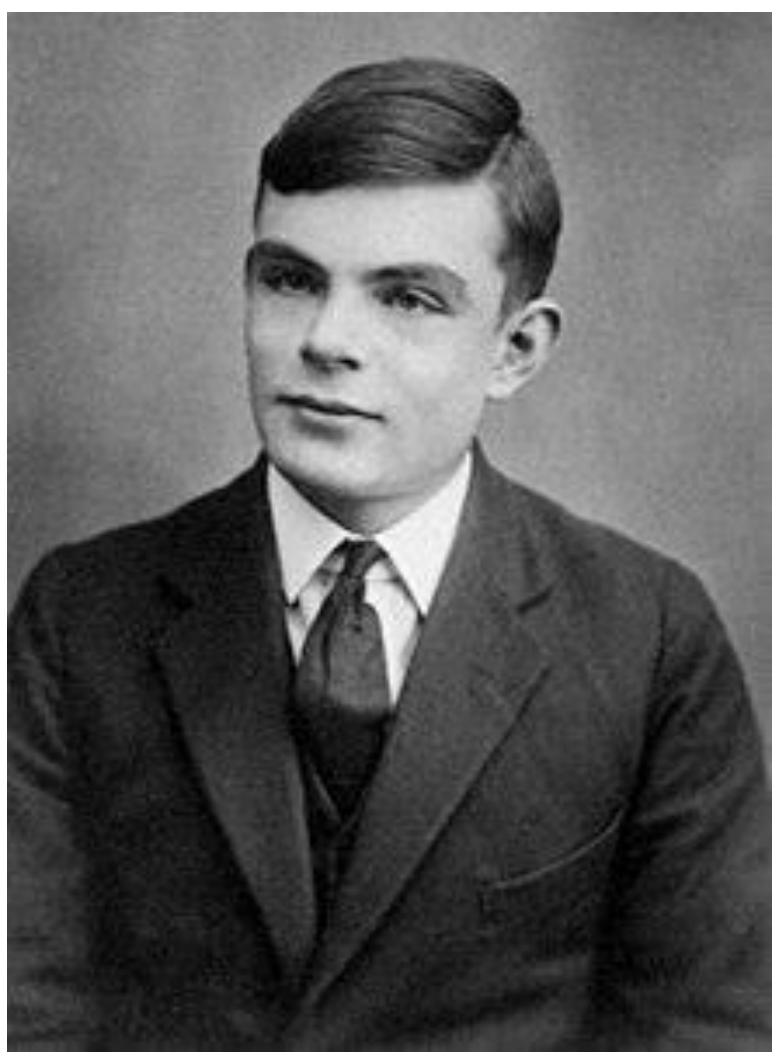




\section{Cracking Enigma: Cribs}

- Turing read through the library of decrypted messages and began to notice that he could predict the plaintext for some messages.

- Example: Germans sent a weather report every morning at 6:00 am. A message of the right length intercepted at 6 am would likely include the German word for weather. Since they followed a specified format, he even knew where "weather" should be located in the message.

- Crib = A plaintext suspected to correspond to a ciphertext

- Enigma could not encipher a letter as itself. If a crib showed any letter on top of itself, it was wrong. This helped immensely in matching cribs to messages. 


\section{Cracking Enigma: Leveraging Cribs}

- Using cribs, Turing identified and mathematically defined loops. This technique was similar to Rejewski's chains.

- Identifying this loop enabled Turing to design a machine that could take a "menu" based off of a loop identified using a crib, then test that configuration in an automated fashion.

- In homage to Rejewski's Bomba, Turing named this machine a Bombe.

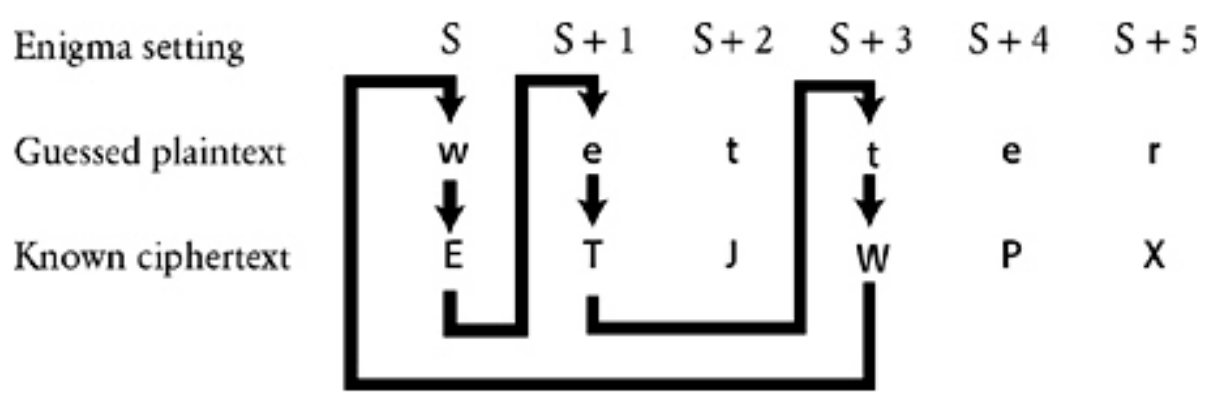

Figure 48 One of Turing's cribs, showing a loop. 


\section{Cracking Enigma: Using the Bombes}

- May 1, 1940 the Germans stopped repeating the message key. The allies were in the dark until August 8, 1940 when the first Bombe arrived.

- By the end of 1942, England had 49 Bombes in operation

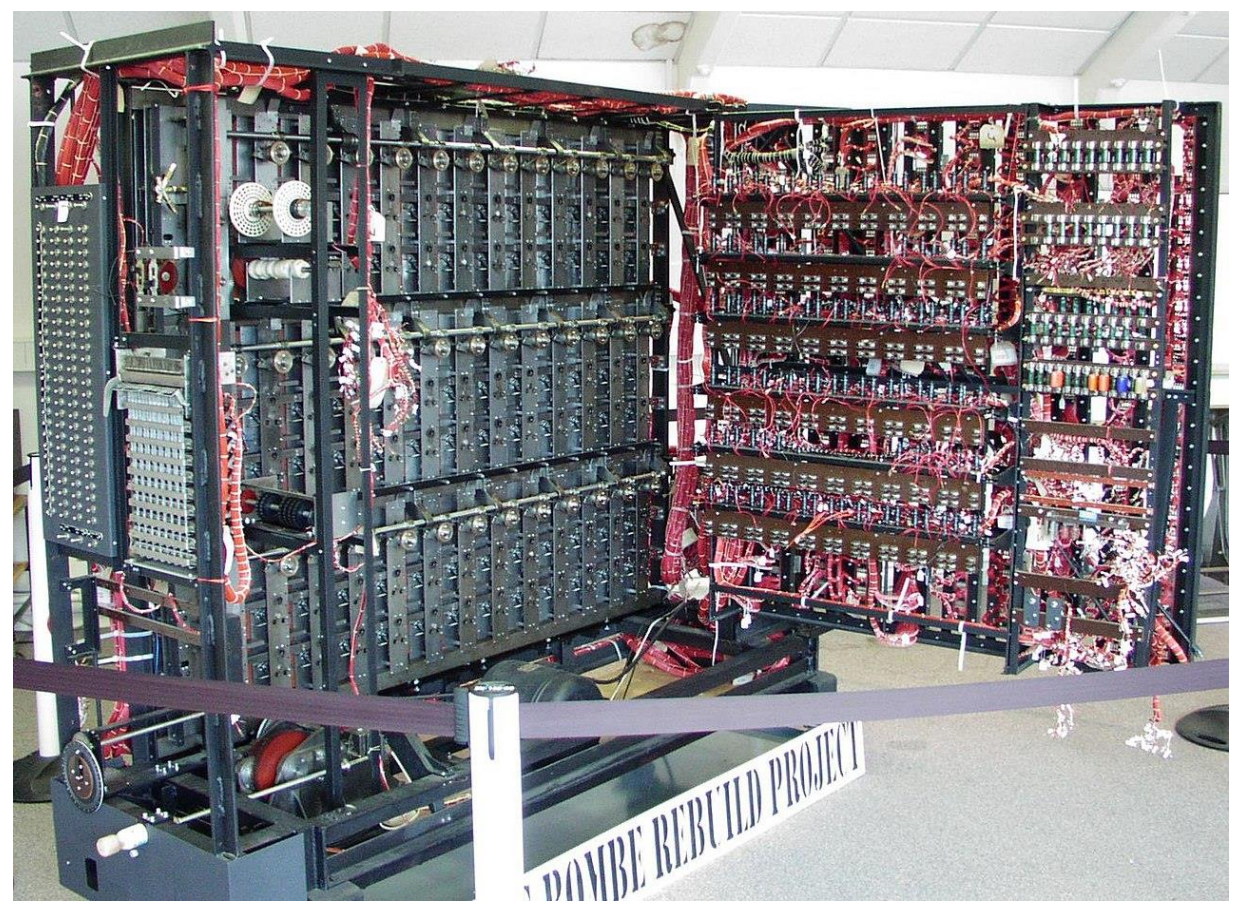




\section{Cracking Enigma: The Kriegsmarine Problem}

- Why couldn't we break it?

- Kriegsmarine had a choice of 8 scramblers, not 5, multiplying the keyspace by a factor of 6 .

- The reflector in the Kriegsmarine Enigma could be fixed in any one of 26 orientations (in normal enigma, it was static), multiplying the keyspace by a factor of 26.

- Kriegsmarine operators were trained in cryptanalysis and avoided stereotypes. It was incredibly difficult to crib kriegsmarine messages 


\section{Cracking Enigma: The Kriegsmarine Problem}

- "Gardening" = Sowing mines to obtain cribs

- British planes drop mines within view of German Navy, prompting them to communicate the location of the mines to the rest of the fleet. Royal Air Force would feed the locations to Bletchley Park for use as cribs.

- "Pinching" = Capturing code books from German ships

- Trained crews to rush into sinking subs to capture their machines and codebooks some success.

- Attacked weather boats and obtained machines and codebooks.

- Measures were taken to make sure Germany never suspected the codebooks had been taken. 


\section{Enigma Post WWII}

- England captured thousands of Enigmas and distributed them among their former colonies as gifts. England routinely broke these communications for years after the war.

- 1974 publication of "The Ultra Secret" signaled the end to the classification of all things Enigma.

- It wasn't until this point that Rejewski knew what he laid the foundation for. 


\section{Other Codebreaking in WWII}

- Enigma was declassified first, and consequently has received the bulk of the attention.

- The United States had its own codebreaking efforts during WWII that made a significant difference in the war, especially in the Pacific Theater. The US broke multiple machine codes similar to Enigma, and developed machines similar to the Bombe.

- Codebreaking was happening prior to Pearl Harbor, but the effort really began in earnest only after the US entered the war. 


\section{Other Codebreaking in WWII - Purple}

- "Purple" was a diplomatic code used for Japanese Foreign office communications.

- Purple used the Type B Cipher Machine - We did not have the plans for this machine.

- Army Signals Intelligence Service (SIS) built the first machine that could decrypt Purple in late 1940. There were 6 distributed around the world by the end of the war.

- Useful in the European theatre because Germany shared their plans with Japan

- Although they received indications that Purple had been broken from both Germany and the USSR, Japan continued to believe that their cipher was unbreakable beyond the end of WWII. 


\section{Japanese Naval Codes}

- Every single Japanese Naval code used in WWII was eventually broken. Codebreaking was a global effort, but the breaking of Japanese codes was led by the United States.

- This includes at least 10 distinct Japanese Naval Codes, the most infamous of which was $\mathrm{JN}-25$.

- Japanese Naval codes were generally codebook based - not machine ciphers. Codebook ciphers break slowly and require immense depth of material.

- Many could not be broken until after Japan mounted major naval operations, post Pearl.

- JN-25 was composed of a codebook with 27,500 entries and a 300 page additive book that was used to superencipher the codebook values.

- Breaking of naval codes relied on cribs common to formal Japanese communication, such as "I have the honor to inform your excellency". 


\section{JN-25}

- JN-25 is most infamous for providing the intelligence necessary to set up the naval battle at Midway, Japan's first defeat after a string of victories in the Pacific.

- JN-25 was FAR from fully decrypted by Midway, but combined with traffic analysis, we had enough to act.

- Operation Vengeance - JN-25 provided the intelligence that enabled the US to shoot down Admiral Yamamoto's plane near the Solomon Islands in 1943 


\section{Other Codebreaking in WWII - Japanese Surrender}

- The Japanese surrendered through the Swiss. The message had to jump through two transmitting stations before it got there, and the US grabbed it from the first.

- The surrender order was encoded in a weak diplomatic code known to allies as JAH (sometimes called LA).

- The US had the message decoded before it even made it to the Japanese Ambassador in Bern 


\section{Other Codebreaking in WWII - Lorentz and Colossus}

- The Lorenz SZ40 machine was used to encrypt communications between Hitler and his generals.

- Tiltman and Tutte (Bletchley Park) discovered a weakness

- Took weeks to break a message by hand, by which point they were typically useless.

- Bombes were great at doing what they were built to do, but not flexible enough to be able to help with Lorenz. That demanded a different machine 


\section{Other Codebreaking in WWII - Lorentz and Colossus}

- Newman invented a machine to help with the Lorenz cipher, but it was deemed impossible to build and shelved. Tommy Flowers disagreed with that decision, and went ahead building it himself at the Post Office Research Center.

- Took 10 months to build it, then delivered it to Bletchley Park on December 8, 1943

- This machine was named Colossus, and it was programmable.

- Post WWII it was destroyed and the plans were burned.

- ENIAC got credit for being this first computer, but with the revelation of recently declassified documents regarding Colossus, a battle rages over which "computer" was "first". 


\section{Lucifer System}

- Horst Feistel was doing crypto research and twice suddenly lost his funding, first at $A F R L$, then at Mitre.

- He finally went to the private sector to work at IBM where he could research without impediment. He developed a crypto system called Lucifer in 1970.

- The Nation Bureau of Standards (NBS, predecessor to NIST) issued a call for proposals for an algorithm to become the Data Encryption Standard (DES) 


\section{Data Encryption Standard (DES)}

- IBM submitted Lucifer to NBS's CFP. It was submitted as a cipher with a key length of 128 bits. It was accepted as DES with a key length of 56 bits.

- Officially adopted November 23, 1976. 


\section{Key Distribution}

- Distributing keys was a logistical nightmare and a cost prohibitive process.

- It's no longer just governments and militaries encrypting their stuff - banks, businesses, scientists - all were trying to keep their info encrypted and this required physically moving keys around.

- Diffie, Hellmann, and Merkle spent over two years focusing on oneway functions and modular arithmetic before developing a solution to the key exchange problem that revolutionized cryptography. 


\section{Diffie-Hellman Key Exchange Algorithm}

- In a 30 minute revelation, Hellman wrote out a way for two people to establish a shared secret without ever transmitting that secret or information that could let it be derived.

- Diffie, Hellman, and Merkle publicly demonstrated their algorithm at a conference in 1976.

- Alice and Bob still have to exchange multiple messages to establish a shared secret - it takes time, but is logistically much easier than meeting to share a key. 


\section{Asymmetric Crypto}

- Diffie-Hellman-Merkle only allowed two entities to establish a shared key, that key then had to be used with some other algorithm for encryption and decryption. We're still encrypting and decrypting with the same key.

- In 1975, Diffie had come up with the idea of an asymmetric cipher encrypting a message with one key, and decrypting it with another. $\mathrm{He}$ didn't have an actual algorithm, just an idea. He published this idea in summer of 1975.

- The idea pretty much died until the key exchange algorithm reinvigorated the field. 


\section{RSA - Rivest, Shamir, Adleman}

- In 1977, Rivest, Shamir, and Adleman found an algorithm to make Diffie's idea a reality.

- Alice creates a public key which she publishes. Bob can use this key to encrypt a message and send it to her, but only her corresponding private key can decrypt it.

- Relies on the fact that there is no known efficient way to factor very large numbers down to their primes. 


\section{Were RSA the first?}

- GCHQ claims two of its employees, Ellis and Cocks, found the RSA algorithm in 1973, 4 years prior to RSA. The idea was ahead of its time and GCHQ neither exploited it nor patented it.

- Revealed publicly, with permission, by Cocks December 18, 1997. Ellis had died at the age of 73 before seeing his work made public. 


\section{Pretty Good Privacy (PGP)}

- In the 1980s, only government and large business owned computers powerful enough to run RSA, and RSA was patented and commercialized. Zimmerman turned his attention towards developing RSA for the masses.

- PGP relies on the RSA algorithm, but rather than using RSA to encrypt the whole message (computationally expensive) it uses RSA to encrypt a key, then that key to perform old fashioned symmetric key cryptography. 


\section{PGP Release}

- Nothing in PGP was original, Zimmerman's genius was to put disparate pieces together and distribute them in a way they could be used by the masses.

- He posted it to an internet bulletin board ignoring RSA's patent and USA export control laws, and there was no going back.

- FBI investigation (went to a grand jury) for illegally exporting a weapon

- Case dropped after 3 years of investigation and legal wrangling.

- RSA furious about patent infringement

- Eventually settled. As Zimmerman became a crusader for freedom against the government, his public image helped him out here.

- Marks the birth of the ever-raging discussion on widespread public use of secure encryption. 


\section{AES- Advanced Encryption Standard}

- The new encryption standard in the US, put into place by NIST in 2001

- Selected in a comparatively open process 


\section{Where does that leave us?}

- Right now the onus is on the cryptanalysts. We have secure encryption. I think.

- Will quantum computing flip the tables?

-Will it deliver the computing power needed to brute force existing algorithms?

- Will it deliver new algorithms that only governments have the financial resources to implement? 


\section{Sources and Recommended Reading}

- Budiansky, S. (2002). Battle of wits: The complete story of codebreaking in World War II. New York: Touchstone.

- JN-25. (n.d.). Retrieved from https://www.nsa.gov/about/cryptologicheritage/center-cryptologic-history/pearl-harbor-review/jn25/

- Mundy, L., \& Calkhoven, L. (2019). Code girls: The true story of the American women who secretly broke codes in World War II. New York: Little, Brown and Company.

- SINGH, D. S. (2011). CODE BOOK: The secret history of codes and code -breaking. 